Adıyaman Üni. Sağlık Bilimleri Derg, 2018;4(2):890-899.

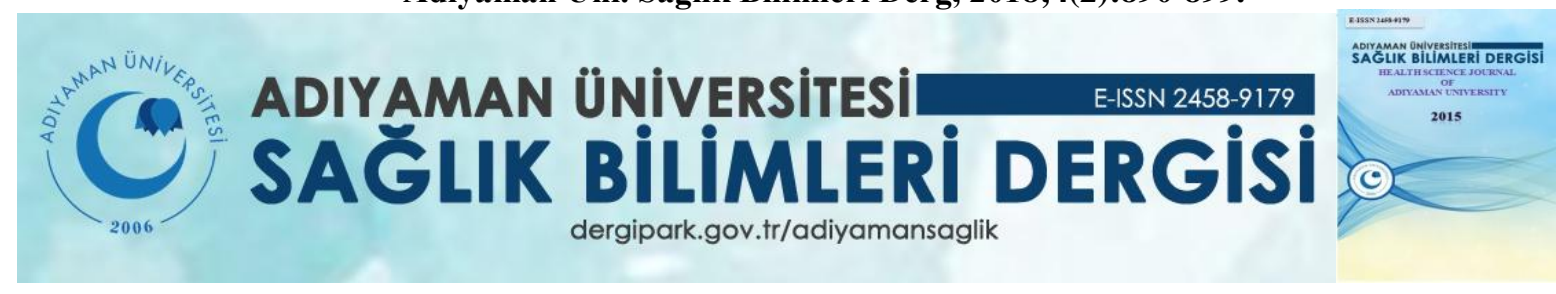

\title{
Araştırma/Research \\ Koroner Arter Baypas Greft Operasyonu Yapılan Obez ve Morbid Obez Hastaların Karşılaştırılması
}

\author{
Ata Niyazi Ecevit ${ }^{1}$, Özgür Altınbaş ${ }^{1}$, Cengiz Güven ${ }^{2}$
}

${ }^{1}$ Eğitim Arştırma Hastanesi, Kalp Damar Cerrahisi Kliniği, Konya

${ }^{2}$ Adıyaman Üniversitesi Eğitim Araştırma Hastanesi, Kalp Damar Cerrahisi Kliniği, Adıyaman

\section{ÖZET}

Amaç: Obezite ve morbid obezite gelişmekte olan ülkelerde önemli bir halk sağlığı sorunu olarak toplumu tehdit etmektedir. Bununla birlikte birçok obez veya morbid obez hastada koroner arter hastalı̆̆ nedeniyle koroner arter baypas greftleme operasyonuna ihtiyaç duyulmaktadır. Biz de bu çalışmada kliniğimizde koroner arter baypas greftleme yaptığımız obez ve morbid obez hastaları dünden bugüne olarak inceleyerek bu hastalarda mortalite ve morbiditeyi artıran risk faktörlerini karşılaşırmayı amaçladık.

Yöntem: 2008 ile 2014 yılları arasında kliniğimizde koroner arter hastalığı nedeni ile takip edilen obez ve morbid obez hastalardan koroner arter baypas greftleme uygulanan hastaları retrospesfik olarak inceledik. Belirtilen yıllar arasında 593 hastaya koroner arter baypas greftleme uygulanmıştı. Bu hastalar obez $(n=69)$ ve morbid obez ( $\mathrm{n}=68$ ) olmalarına göre iki gruba ayrıldı. Morbid obez hastaların vücut kitle indeksleri $35 \mathrm{~kg} / \mathrm{m}^{2} \mathrm{ve}$ vücut yüzey alanları $2.0 \mathrm{~kg} / \mathrm{m}^{2}$ 'nin üzerinde idi. Obez hastaların ise vücut kitle indeksleri $25-35 \mathrm{~kg} / \mathrm{m}^{2}$ ve vücut yüzey alanları $1.8-2.0 \mathrm{~kg} / \mathrm{m}^{2}$ arasındaydı.

Bulgular: Hastaların median yaşları obez hasta grubunda $61,20 \pm 9,04$, morbid obez hasta grubunda $60,54 \pm 10,65$ idi. Obez hasta grubunda diabetes mellitus 32 (\%46,4), morbid obez hasta grubunda ise $20(\% 29,4)$ hastada mevcuttu ( $\mathrm{p}=0.041)$. Anstabil anjina pektoris şikâyeti olan hasta sayısı obez hasta grubunda $20(\% 29)$ morbid obez hasta grubunda ise $10(\% 14,7)$ 'du $(\mathrm{p}=0.043)$. Hastanede kalış süresi obez hasta grubunda 10 gün morbid obez hasta grubunda ise 12 gün idi. 30 günlük mortalite her iki grupta eşit olmakla birlikte $\% 4,4$ idi.

Sonuç: Morbid obez ile obez hastalar karşılatırıldığında morbid obez olanlarda koroner arter baypas greftleme için artmış mortalite ve morbiditeye sebep olacak risk faktörleri olmadığı düşünülmektedir.

Anahtar Kelimeler: koroner arter baypas greftleme; morbid obezite; obezite

\begin{tabular}{l}
\hline Yazışmadan Sorumlu Yazar \\
\hline Özgür Altınbaş \\
Eğitim Arştırma Hastanesi, Kalp Damar Cerrahisi \\
Kliniği, Konya \\
Tel: 05056570577 \\
Email: $\underline{\text { ozgur_altinbas@ yahoo.com }}$ \\
\hline
\end{tabular}

DOI: $10.30569 /$ adiyamansaglik.435696

\begin{tabular}{ll}
\hline Geliş Tarihi: & 22.06 .2018 \\
\hline Kabul Tarihi: & 13.07 .2018 \\
\hline
\end{tabular}




\title{
Comparison of Obese and Morbidly Obese Patients Underwent Coronary Artery Bypass Graft Operations
}

\begin{abstract}
Aim: Obesity and morbid obesity threatens society as a major public health problem in developing countries. However, for many obese or morbidly obese patients, coronary artery bypass grafting operation is needed due to coronary artery disease. In this study, we aimed to evaluate the risk factors which increase mortality and morbidity in these obese and morbidly obese patients underwent coronary artery bypass grafting in our clinic.

Materials and methods: Obese and morbidly obese patients underwent coronary artery bypass grafting due to coronary artery disease in our clinic between 2008 and 2014 were analyzed retrospectively. 593 patients underwent coronary artery bypass grafting between the years specified. They were divided into two groups as obese $(n=69)$ and morbidly obese $(n=68)$ patient. Each morbidly obese patients has a body mass index more than $35 \mathrm{~kg} / \mathrm{m} 2$ and a body surface area more than 2,0 $\mathrm{kg} / \mathrm{m} 2$. Each obese patients has a body mass indexes between $25-35 \mathrm{~kg} / \mathrm{m} 2$ and a body surface area between $1,8-2.0 \mathrm{~kg} / \mathrm{m}^{2}$.
\end{abstract}

Results: The median age of the patients was $61,20 \pm 9.04$ in the obese patient group and $60,54 \pm 10,65$ in morbidly obese patient group. Diabetes mellitus was present in $32(46,4 \%)$ patients in obese patient group, and in $20(29,4 \%)$ patients in morbidly obese patient group $(\mathrm{p}=0.041)$. The number of patients with complaints of chest pain was 20(29\%) in the obese patient group and $10(14.7 \%)$ in morbidly obese patient group $(\mathrm{p}=0.043)$. Duration of hospitalization was 12 days in obese patient group and 10 days in morbidly obese patient group. 30-day mortality was equal in both groups with $4.4 \%$.

Conclusion: According to our study there was not any risk factor which can increase mortality and morbidity in morbidly obese patients when they compared with obese patients

Keywords: Coronary artery by-pass grafting; morbid obesity; obesity 


\section{Giriş}

Obezite önemli bir halk sağlığı sorunu olarak görülmektedir, özellikle diabetes mellitus(DM), hipertansiyon(HT), koroner arter hastalığı(KAH) için predispozan faktör olarak karşımıza çıkmaktadır (1). Obesite, koroner arter baypas greft (KABG) hastalarında artmış mortalite ve morbidite için bir risk faktörü olarak görülmektedir. Literatürde bazı kaynaklar morbid obeziteyi artmış mortaliteyle ilişkilendirirken, morbid obez hastalarda, obez hastalara göre belirgin risk artışı olmadığını gösteren yayınlar da mevcuttur (2). Oreopoulos ve arkadaşları kilolu veya morbid obez hastaların KABG sonrası tüm nedenlere bağlı mortalite ile ilişkisini yansız olarak gösterdiler (3). Biz de bu çalışmada kliniğimizde KABG operasyonu yaptığımız obez ve morbid obez hastları retrospektif olarak inceledik ve cerrahi açısından artmış mortalite ve moribiditeyi ile ilişkili faktörleri karşılaştırmayı amaçladık.

\section{Gereç ve Yöntemler}

Nisan 2008 ile mayıs 2014 yılları arasında, tek merkezde aynı cerrahi ekip tarafından KABG operasyonu yapılan 593 hasta retrospektif olarak incelendi. Preoperatif risk skorlamaları "Society of Thorasic Surgery" (STS) kritelerine göre yapıldı. Bu kriter içinde; yaş, cinsiyet, kilo, boy, sigara kullanımı, diabete mellitus varlığı, hiperlipidemi varlığı, hipertansiyon öyküsü, artmış serum kreatinin değerleri, drenaj miktarları ve cerrahi zamanlama vardı.

Hastaların vücut kitle indeksleri(VKİ), vücut yüzey alanları(VYA), hiperlipidemi varlığı, hipertansiyon öyküsü, kronik obstrüktif akciğer hastalığı öyküsü, DM öyküsü, anstabil angina pektoris varlığı, ejeksiyon fraksiyonları(EF), inotrop ihtiyac1 olup olmaması, serum kreatin değerleri incelendi. İntraoperatif veriler olarak; kros-klemp(KK) süreleri, kardiyopulmoner bypass(CPB) süreleri, intraaortik balon pompası ihtiyacı, kan ve kan ürünü transfüzyon miktarı ve mekanik ventilasyon süreleri incelendi. Postopeatif veriler; sternal yara 
enfeksiyonu, sepsis, geçici iskemik atak(TIA), uzamış mekanik ventilasyon ihtiyacı( $>24$ saat), pulmoner tromboembolik olay(PTE), pnömoni, böbrek yetmezliği, tamponad, cerrahi gerektirecek postoperatif kanama, 30 günlük mortalite, hastanede kalış süreleri, yoğun bakımda kalış süreleri incelenmiştir.

\section{İstatistiksel Analiz:}

Sürekli değişkenlerin normal dağılım gösterip göstermedikleri Shapiro-Wilks testiyle incelenmiştir. Sürekli değişkenler bakımından grupların karşılaştırılmasında, değişkenin normal dağılım gösterip göstermemesine bağlı olarak Independent Samples t test veya MannWhitney $U$ test kullanılmıştır. Kategorik değişkenler bakımından grupların karşılaştırılmasında ise Chi-square veya Fisher's Exact testlerinden yararlanılmıştır. İstatistik analizler PASW v.18 paket programı ile yapılmış ve önemlilik düzeyi $\mathrm{p}<0.05$ olarak dikkate alınmıştır.

\section{Bulgular}

Tek merkezden Nisan 2008 ve Mayıs 2014 yılları arasında kardiyopulmoner bypass eşliğinde izole KABG yapılan 593 hasta retrospektif olarak incelendi. Hastalar, obez ve morbid obez olarak iki gruba ayrılarak preoperatif, intraoperatif ve post operatif verileri ayrı ayrı incelendi. Her iki hasta grubunda komorbid özellik olarak hipertansiyon, hiperlipidemi, kronik obstriktif akciğer hastalığı varlığı arasındaki fark istatistiksel olarak anlamlı değilken, diabetes mellitus $(\mathrm{p}<0.041)$ anstabil angina pektoris varlığı $(\mathrm{p}<0.043) \quad$ ve kronik böbrek yetmezliği $(\mathrm{p}<0.016)$ mevcudiyeti arasındaki fark istatistiksel olarak anlamlı idi. (Tablo 1) 


\section{Tablo 1. Preoperatif veriler}

\begin{tabular}{|c|c|c|c|}
\hline & Obeze (n:69) & Mobeze (n:68) & $\mathbf{p}$ \\
\hline Yaş & $61,20 \pm 9,04$ & $60,54 \pm 10,65$ & 0,697 \\
\hline BMİ & $28,98 \pm 2,73$ & $37,09 \pm 2,09$ & $<0,001$ \\
\hline BSA & $1,91 \pm 0,04$ & $2,10 \pm 0,08$ & $<0,001$ \\
\hline Erkek & $55(79,7)$ & $53(77,9)$ & 0,800 \\
\hline Kadın & $14(20,3)$ & $15(22,1)$ & \\
\hline Acil & $4(5,8)$ & $10(14,7)$ & 0,085 \\
\hline PAH & - & - & - \\
\hline HL & $7(10,1)$ & $12(17,6)$ & 0,204 \\
\hline HT & $31(44,9)$ & $31(45,6)$ & 0,938 \\
\hline DM & $32(46,4)$ & $20(29,4)$ & 0,041 \\
\hline KBY & $0(0,0)$ & $3(4,4)$ & 0,120 \\
\hline КОАН & $6(8,7)$ & $7(10,3)$ & 0,750 \\
\hline USAP & $20(29,0)$ & $10(14,7)$ & 0,043 \\
\hline LMCA $<50$ & $63(91,3)$ & $64(94,1)$ & 0,745 \\
\hline LMCA > =50 & $6(8,7)$ & $4(5,9)$ & \\
\hline EF 21-40 & $21(30,4)$ & $12(17,6)$ & 0,113 \\
\hline EF 41-60 & $38(55,1)$ & $49(72,1)$ & \\
\hline$E F>60$ & $10(14,5)$ & $7(10,3)$ & \\
\hline İABP & $3(4,3)$ & $5(7,4)$ & 0,493 \\
\hline İnotrop & $26(37,7)$ & $23(33,8)$ & 0,638 \\
\hline Kreatinin & $0,98 \pm 0,28$ & $1,17 \pm 0,56$ & 16 \\
\hline
\end{tabular}

BMí: Vücut Kitle İndeksi, LMCA: Sol Ana Koroner Arter, BSA:Vücut Yüzey Alanı, EF: Ejeksiyon Fraksiyonu, PAH: Periferik Arter Hastalığı, İABP:İntraaortik Balon Pompası, HL: Hiperlipidemi, HT: Hipertansiyon, DM: Diyabetes Mellitus, KBY:Kronik Böbrek Yetmezliği, KOAH: Kronik Obstruktif Akciğer Hastalığı, USAP: Anstabil Anjina Pektoris. 
VKİ $25-30 \mathrm{~kg} / \mathrm{m}^{2}$ arasında olan hastalar kilolu, $30-35 \mathrm{~kg} / \mathrm{m}^{2}$ arasında olanlar obez, $\geq 35 \mathrm{~kg} / \mathrm{m}^{2}$ olanlar ise morbid obez olarak sınıflandırılmıştır.

Hastaların 68'inde morbid obezite mevcuttu (VKI > $35 \mathrm{~kg} / \mathrm{m}^{2}$ ve VYA > 2.0m²). 69 hastada ise obezite mevcuttu (VKİ: $30-35 \mathrm{~kg} / \mathrm{m}^{2}$ ve VYA: $1.8-2 \mathrm{~m}^{2}$ ).

Hastaların intraoperatif verileri içerinde kardiyopulmoner bypass süreleri ve kros-klemp sürelerinde her iki grup arasında istatisksel olarak anlamlı farklılık yoktu (Tablo 2). Ancak hastaların toplam hastanede kalış süreleri $(\mathrm{p}<0.001)$ ve taze donmuş plazma(TDP) kullanımına $(\mathrm{p}<0.016)$ bakıldığında iki grup arasında arasında istatistiksel anlamlı bir fark izlendi. Diğer kan ve kan ürünlerinin kullanımı açısından iki grup arasındaki fark istatistiksel olarak anlamlı değildi. Taze donmuş plazma kullanımının preoperatif kreatin değerleri yükse k hastalarda daha fazla olduğu görüldü (Tablo 3).

Tablo 2: Intraoperatif Veriler

\begin{tabular}{cccc}
\hline & Obeze (n:69) & Mobeze (n:68) & p \\
\hline KPB süresi & $106,25 \pm 34,46$ & $100,87 \pm 49,39$ & 0,461 \\
\hline Kros- klemp Süresi & $59,43 \pm 19,39$ & $56,87 \pm 22,97$ & 0,481 \\
\hline
\end{tabular}

KPB: Kardiyopulmoner Baypas (dk), Kros-klemp (dk)

Tablo 3. Postoperatif Veriler

\begin{tabular}{cccc}
\hline & Obeze (n:69) & Mobeze (n:68) & p \\
\hline Total Yatıs (gün) & $10(2-47)$ & $12(4-95)$ & $<0,001$ \\
\hline YB Süresi (gün) & $2(1-36)$ & $2(1-18)$ & 0,749 \\
\hline YB Kan İhtivacı & $67(97,1)$ & $66(97,1)$ & 0,999 \\
\hline Kan Savısı $^{*}$ & $4(1-12)$ & $4(1-21)$ & 0,533 \\
\hline YB TDP ihtivacı $^{*}$ & $67(97,1)$ & $66(97,1)$ & 0,999 \\
\hline TDP Savısı $^{*}$ & $6(1-16)$ & $3(1-22)$ & 0,016 \\
\hline YB Trombosit & $1(1,4)$ & $2(2.9)$ & 0,619 \\
\hline Trombosit Savısı $^{*}$ & 3 & 2 & 0,667 \\
\hline YB: Yoğun Bakım, TDP: Taze Donmuş Plazma $^{*}$ Tatbik edilen ünite
\end{tabular}


Postoperatif süreçte her iki gruptaki hastalar; sternal enfeksiyon, septisemi, geçici iskemik atak ve diğer serebrovasküler olaylar, diyaliz gereksinimi, tamponad, cerrahi gerektirecek kanama olması açısından incelendi. Elde edilen sonuçlar tablo 4te karşılaştırıldı. İntraoperatif mortalite ve erken dönem (<30 gün ) mortalite oranları da tablo 4'te karşılaştırıldı.

Tablo 4. Erken Dönem Komplikasyonlar

\begin{tabular}{|c|c|c|c|}
\hline & Obeze (n:69) & M.obeze (n:68) & $\mathbf{p}$ \\
\hline Sternal Yara Enfeksiyonu & $5(7,2)$ & $3(4,4)$ & 0,718 \\
\hline Sepsis & $3(4,3)$ & $4(5,9)$ & 0,718 \\
\hline Geçiçi İskemik Atak & $1(1,4)$ & $3(4,5)$ & 0,362 \\
\hline Diyaliz İhtiyacı & $3(4,3)$ & $6(8,8)$ & 0,325 \\
\hline Pulmoner Trom & $1(1,4)$ & $2(2,9)$ & 0,619 \\
\hline Pnömoni & $3(4,3)$ & $8(11,8)$ & 0,110 \\
\hline Tamponad & $1(1,4)$ & $3(4,4)$ & 0,366 \\
\hline Kanama & $4(5,8)$ & $4(5,9)$ & 0,999 \\
\hline Ölüm & $1(1,4)$ & $3(4,4)$ & 0,366 \\
\hline$<30$ gün Mortalite & $3(4,3)$ & $3(4,4)$ & 0,999 \\
\hline Drenaj miktarları (cc) & 750 & 870 & 0,824 \\
\hline
\end{tabular}

\section{Tartışma}

Obesitenin gelişmekte olan ülkeler için hala önemli bir sağlık sorunu olduğu ortadır. $\mathrm{Bu}$ nedenle $\mathrm{VKI}>30 \mathrm{~kg} / \mathrm{m}^{2}$ olan hastalarda cerrahi girişimler riskli kabul edilmekle beraber, Engelman ve arkadaşları tarafından yapılan bir çalışmada VKİ $>20 \mathrm{~kg} / \mathrm{m}^{2}$ olup kardiyak cerrahi geçiren hastalarda genel popülasyonla karşılaştırıldığında mortalitede artış gözlenmiştir(\%10- 
\%4) (4). Reeves ve arkadaşları ise VKI $>20 \mathrm{~kg} / \mathrm{m}^{2}$ olan hastalarda izole KABG için operatif mortaliteyi \%6.8 olarak belirlemişlerdir. Aynı çalışmada normal VKİ olan hastaların izole KABG için operatif mortalitesi $<\% 1$ olarak saptanmıştır (5). Ek olarak elektif vakalarda obez ve morbid obez hastalarla ilgili solunum egzersizleri, beslenme değişiklikleri gibi alınabilecek preoperatif önlemlerin morbidite ve mortalite üzerinde olumlu etkileri olduğuna yönelik çalışmalar mevcuttur $(6,7)$.

Kuduvalli ve arkadaşlarının yaptıkları çalışmada kardiyak cerrahi geçiren BMI> $35 \mathrm{~kg} / \mathrm{m}^{2}$ hastalarda yoğun bakımda kalış süresi ve mekanik ventilasyon süresinin arttığını göstermişlerdir (8). Bizim çalışmamızda hastaların hastanede kalış süreleri açısından iki grup arasında istatistiksel olarak anlamlı $(\mathrm{p}<0.001)$ fark mevcut iken ventilasyon süreleri açısından istatistiksel olarak anlamlı fark gözlenmemiştir. Buradaki farklılıkta hastaların preoperatif fizik kondisyon ve mobilizasyon kapasitesinin önemli yer tuttuğu görülmüştür. Hastaların postoperatif akut böbrek yetmezliğine bağlı diyaliz gereksinimi morbid obez hastalarada sayısal olarak daha fazla görülmesine rağmen aradaki fark istatistiksel olarak anlamlı değildi. C.H. Wigfield ve arkadaşları yaptıkları çalışmada obez ve morbid obez hastaların KABG sonrası diyaliz ihtiyaçlarının daha fazla olmadığını belirtmişlerdir (9). Bir başka çalışmada ise yine VKİ ile akut böbrek yetmezliği arasında bir ilişkili olmadığı saptanmıştır (10). Sternal yara enfeksiyonu oranı obez hasta grubunda sayıca yüksekti ancak fark istatistiksel olarak anlamlı değildi. C.H. Wigfield ve arkadaşları, postoperatif mediastinit ve sternal yara enfeksiyonun DM ve perioperatif hiperglisemisi olan hastalarda sıkça görüldügünü yaptıkları çalışmada belirtmişlerdir (9). Kan ve kan ürünleri kullanımı obez ve morbid obez hasta grupları arasında farklılık göstermedi, ancak taze donmuş plazma kullanımı açısından iki grup arasında istatistiksel olarak anlamlı fark vardı. Acil operasyonlarda, ejeksiyon fraksiyonu düşük hastalarda, kardiyopulmoner baypas zamanı uzun olan hastalarda taze donmuş plazma 
kullanımı daha fazlaydı. Gökcen ve arkadaşları yaptıkları çalışmada kros-klemp zamanının obez ve morbid obez hasta grupları arasında farklı olmadığını gösterdiler (11). Literatürle uyumlu olarak bizim çalışmamızda da hastaların kardiyopulmoner baypas ve kros-klemp süreleri incelendiğinde gruplar arasında anlamlı fark gözlenmedi.

Gruplar arasında hastaların İABP kullanımı arasındaki fark istatistiksel olarak anlamlı değildi, intraoperatif eksitus olan hastalar morbid obez grubunda sayıca fazlaydı ancak fark istatistiksel olarak anlamlı değildi. Eksitus olan hastalar anstabil angina pektorisi olan akut iskemik atağı olan hastalardı. Her iki grup arasında erken mortalite ( $<30$ gün) oranlarındaki fark istatiksel olarak anlamlı değildi. Yapılan çalışmalarda obezitenin hastane mortalitesi ve postoperatif mortaliteyi etkileyen bir risk faktörü olmadığı gösterilmiştir $(1,6)$. Yine başka bir çalışmada ciddi obezitenin KABG olacak hastalarda postoperatif morbidite ve mortaliteyi etkileyen bir değişken olmadığı gösterilmiştir (12). Ancak literatürde bunun aksini savunan yazılarda mevcuttur. Grayson ve arkadaşları obez hastaları obez olmayanlarla karşılaştırdıklarında obezitenin, artmış morbidite ve hastanede kalış süreleri için önemli bir risk faktörü olduğu savunmuşlardır (13).

Özetle bu çalışma obezitenin tüm ülkeler için bir sağlık sorunu olmaya devam etmesi yanında obez ve morbid obez hastalara karşı cerrahi ekiplerin elektif vakalarda olusturmuş oldukları preoperatif ön hazırlık sürecinin de morbidite ve mortalite oranlarını olumlu etkilediği ve başarılı operasyonların yapılabilirliğini göstermiştir. Literatürde konuyla ilgili farklı görüşler bulunmakla birlikte, bizim çalışmamız morbid obezitenin KABG için ek bir risk oluşturmadığı fikrini vermektedir. 


\section{KAYNAKLAR}

1. Moulton MJ, Creswell LL, Mackey ME, Cox JL, Rosenbloom M. Obesity is not a risk factor for significant adverse outcomes after cardiac surgery. Circulation 1996;95(Suppl 9):1187-92.

2. Christakis GT, Weisel RD, Buth KJ, Fremes SE, Rao V, Panagioto- poulos KP, Ivanov J, Goldman BS, David TE. Is body size the cause of poor outcomes of coronary artery bypass operations in women? J Thorac Cardiovasc Surg 1995;110:1344-58.

3. Oreopoulos A, Padwal R, Norris CM, Mullen JC, Pretorius V, Kalantar-Zadeh K. Effect of obesity on shortand long-term mortality postcoronary revascularization: a meta-analysis. Obesity (Silver Spring) 2008; 16:442-50.

4. Engelman DT, Adams DH, Byrne JG, et al. Impact of body mass index and albumin on morbidity and mortality after cardiac surgery. J Thorac Cardiovasc Surg 1999;118:866-73.

5. Reeves BC, Ascione R, Chamberlain MH, Angelini GD. Effect of body mass index on early outcomes in patients undergoing coronary artery bypass surgery. J Am Coll Cardiol 2003;42:668-76.

6. Llorens J, Rovira L, Ballester M, Moreno J, Hernandez LJ, Santonja FJ, Cassinello N, Ortega J. Preoperative inspiratory muscular training to prevent postoperative hypoxemia in morbidly obese patients undergoing laparoscopic bariatric surgery. A randomized clinical trial. Obes Surg 2015; 25(6): 1003-9.

7. Santo MA, Riccioppo D, Pajecki D, Cleva R, Kawamoto F, Cecconello I. Preoperative weight loss in superobese patients: study of the rate of weight loss and its effects on surgical morbidity. Clinics (Sao Paulo) 2014; 69 (12): 828-834.

8. Manoj K, Antony DG, Aung YO, Brian MF and Abbas R. Risk of morbidity and in-hospital mortality in obese patients undergoing coronary artery bypass surgery. Eur J Cardiothorac Surg 2002; 22(5):787-793.

9. Christopher H, Wigfield R, Joshua D, LindseyAM, Parmjeet S, Chopra NM, Edwards S, Robert B. Love Is extremeobesity a risk factor for cardiac surgery? An analysis of patients with a BMI $>40 \mathrm{~kg} / \mathrm{m} 2$. Eur J Cardiothorac Surg 2006; 434-440.

10. Koshal A, Hendry P, Raman SV, Keon WJ. Should obese patients not undergo coronary artery surgery? Can J Surg 1985;28:331-4.

11. Gökcen O, Yesim B, Serap AA, Murat S, Serap S, Sahin S, Zuhal A, Ergin E. Coronary artery bypass graft operation can be performed safely in obese patients. European Journal of Cardio thorasic surgery 25(2004) 212-217.

12. Brandt M, Harder K, Walluscheck KP, Schottler J, Rahimi A, Moller F, Cremer J. Severe obesity does not adversely affect perioperative mortality and morbidity in coronary artery bypass surgery. Eur J Cardiothorac Surg 2001;19:662-666

13. Grayson AD, Oo AY, Fabri BM, Rashid A. Risk of morbidity and in hospital mortality in obese patients undergoing coronary artery bypass surgery. Eur J Cardiothorac Surg 2002;22:787-793 